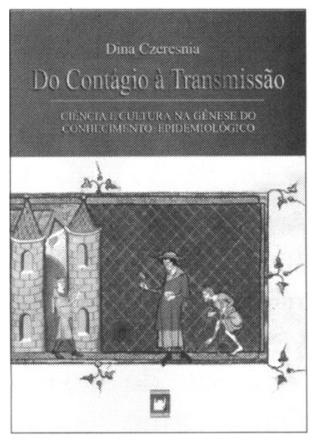

Dina Czeresnia Do contágio à transmissão: ciência e cultura na gênese do conbecimento epidemiológico Editora Fiocruz, 1997, $123 \mathrm{p}$.

\section{Epidemias, infecção e contágio}

\author{
Kenneth Rochel de Camargo Jr. \\ Doutor em saúde coletiva \\ Professor adjunto do IMS/UERJ \\ Rua Jaceguai, 66/402 \\ 20550-150 Rio de Janeiro - RJ \\ e-mail: kenneth@uerj.br
}

cações entre sãos e doentes, pacientes e médicos, bons e maus, é estar a um passo do conservadorismo e, mais do que isso, do fascismo.

Como dizia Marx, a história da cultura é a história da educação dos nossos cinco sentidos. Neste percurso, Sander Gilman revela-se um interlocutor indispensável e um intelectual corajosamente incômodo.

\section{$\mathrm{O}$} surgimento da epidemia de HIV/Aids recolocou em primeiro plano questões que pareciam superadas para a medicina, ou ao menos relegadas aos rincões mais pobres do planeta, onde as doenças infecciosas e parasitárias continuavam (como continuam) seguindo. como causas importantes de morbimortalidade.

A irrupção de uma 'praga' moderna também reviveu antigos fantasmas, como a discriminação, a demonização de 'outros' responsabilizados pelo seu aparecimento, o pânico da contaminação. Estas respostas surgiram através de todos os recortes sociais possiveis, não poupando nem mesmo aqueles que supostamente teriam o conhecimento técnico para evitá-las.

O trabalho de Dina Czeresnia ajuda a entender e colocar em perspectiva as respostas sociais à epidemia de HIV/Aids - e entendemos os desenvolvimentos técnico-científicos também como respostas sociais - ao historiar uma série de linhas, aparentemente desconexas, que levam às modernas construções de epidemias, infecção e contágio.

Um primeiro mérito deste livro é articular termos usualmente abordados isoladamente, como o desenvolvimento do conceito moderno de organismo e seu papel no entendimento corrente sobre os processos infecciosos; a visão cultural do contágio e a constituição histórica de um conhecimento sobre as epidemias; as origens históricas da epidemiologia e as disputas teóricas entre contagionistas e anticontagionistas.

Neste último particular, a autora faz um importante trabalho de especificação de quais eram, exatamente, os pontos de divergência entre estas duas correntes de pensamento, mostrando, por exemplo, como o enfim triunfante contagionismo na verdade trazia uma nova concepção, representada pela incorporação da perspectiva microbiologista, constituindo um novo conceito, o de transmissão. Em lugar de um 'contágio' inespecífico 
(etimologicamente ligado à idéia de contato físico), as doenças infecciosas caracterizar-se-iam pela possibilidade de transmissão de agentes microscópicos de um indivíduo a outro.

Outro aspecto importante deste livro é a recuperação das idéias de autores praticamente desconhecidos, Crookshank e Hamer, epidemiologistas do início deste século, com idéias surpreendentemente avançadas mesmo para os nossos dias, propondo uma epidemiologia que levasse em consideração não apenas os agentes patogênicos microscópicos, mas também o que chamavam de "constituição epidêmica".

Um último aspecto meritório de destaque, presente ao longo de todo o desenvolvimento do livro, é a concepção de uma ciência com determinações complexas, que, longe de ter uma relação de dominação com a cultura mais geral, ou de completo desconhecimento, mostra amplas interações, em que ambas moldam correspondentemente seus discursos e suas práticas. Desse modo, as visões de um dado momento histórico sobre as epidemias, suas causas e seu enfrentamento, longe de espelhar passivamente o discurso da autoridade acadêmica, mantêm com esta um diálogo dinâmico, de interação.

É esta concepção, fundamentalmente, que abre espaço para a investigação teórica da autora, que vai da biologia à história, da epidemiologia à filosofia, incursionando até mesmo por alguns aspectos teóricos da psicanálise. $\mathrm{O}$ resultado é um painel amplo que retrata a multiplicidade de sentidos que se esconde por trás de termos técnicos de aparente simplicidade, que por sua vez ajuda a explicar por que o pânico, o preconceito e a discriminação são também por vezes 'contagiosos', mesmo para aqueles que, em virtude do seu treinamento profissional, suporíamos 'imunes'.

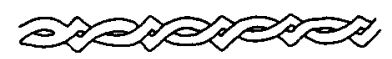

